The 13th European Nutrition Conference, FENS 2019, was held at the Dublin Convention Centre, 15-18 October 2019

\title{
Oranges as fruit and as juice
}

\author{
$\underline{\text { Katarzyna Stos }}^{1}$, Beata Przygoda ${ }^{1}$, Miroslaw Jarosz ${ }^{1}$, Ewa Matczuk ${ }^{1}$, Barbara Groele ${ }^{2}$, \\ Sylwia Skapska ${ }^{3}$ and Jaroslaw Markowski ${ }^{4}$ \\ ${ }_{1}^{1}$ Institute of Food and Nutrition, Warsaw, Poland, \\ ${ }^{2}$ The Polish Association of Juice Producers, Warsaw, Poland, \\ ${ }^{3}$ Institute of Agricultural and Food Biotechnology, Warsaw, Poland and \\ ${ }^{4}$ Research Institute of Horticulture in Skierniewice, Skierniewice, Poland
}

\section{Abstract}

Vegetables and fruits should form the basis of everyday diet. In some countries one of five recommended daily portions of vegetables and fruit can be a glass $(200 \mathrm{ml})$ of juice. The aim of the study was to analyse the composition of orange juice from concentrate and compare it with the content of selected nutrients in oranges.

The study material were orange juices from concentrate, commercially available in Poland. The study was carried out in 2010-2018 at the Agriculture and Food Industry Biotechnology Institute and the Horticulture Institute in Skierniewice, Poland. The content of the following nutrients was investigated: vitamin $\mathrm{C}$, folates, b-carotene, sodium, potassium, calcium, magnesium, glucose, fructose, sucrose, dietary fiber as well as energy content.

The content of vitamin $C$ in orange juice from concentrate was $35 \mathrm{mg} / 100 \mathrm{ml}$. Folate content was $23 \mathrm{mg} / 100 \mathrm{ml}$ of juice. The studied juice contained the following amounts of minerals: sodium $(3 \mathrm{mg} / 100 \mathrm{ml})$, potassium $(185 \mathrm{mg} / 100 \mathrm{ml})$, calcium $(13 \mathrm{mg} / 100 \mathrm{ml})$ and magnesium $(11 \mathrm{mg} / 100 \mathrm{ml})$. The total amount of sugars contained in the analysed juice was $8.8 \mathrm{~g} / 100 \mathrm{ml}$. Compared to fresh oranges, the content of sodium, potassium, magnesium, b-carotene and sugars was similar. The content of vitamin $\mathrm{C}$, folates and calcium was slightly higher in fruits. Dietary fiber amount was much higher in orange fruit than in juice. The energy value of both products was similar: $42 \mathrm{kcal} / 100 \mathrm{ml}$ in juice and $47 \mathrm{kcal} / 100 \mathrm{~g}$ in oranges.

The study showed that orange juice from concentrate is a source of important nutrients: vitamin C, folate and potassium. Their content in orange juice from concentrate is similar to that in fresh oranges. Dietary fiber amount was much higher in orange fruit than in juice.

\section{Conflict of Interest}

There is no conflict of interest 